\title{
STUDY OF POSTERIOR INTERVENTRICULAR ARTERY IN HUMAN CADAVERIC HEARTS
}

\section{Kannan Subramanian ${ }^{1}$, Komala Nanjundaiah $* 2$}

${ }^{{ }_{1}}$ Assistant professor, Department of Anatomy, Karpagam Faculty of Medical Sciences \& Research, Coimbatore, India.

${ }^{2}$ Associate Professor, Department of Anatomy, M.S.Ramaiah Medical College, M.S.R Nagar, Bangalore, Karnataka, India.

\section{ABSTRACT}

Back ground: Human heart is supplied by coronary arteries. Variations in the branching pattern of coronary arteries can affect the blood supply to the heart.

Context: Origin of posterior interventricular artery determines the coronary dominance. Prognosis of inferior wall infarcts is related to coronary dominance.

Purpose: The present study was conducted in 60 specimens of human cadaveric hearts and observed for number, origin, and level of termination of posterior interventricular artery.

Results: Present study was conducted in 60 specimens and right coronary dominance was observed in $91.7 \%$. The incidence of left coronary dominance was observed in $6.7 \%$ and co-dominance was found in $1.7 \%$.

Conclusion: Posterior interventricular artery has special importance as it determines the coronary dominance. The blood supply of the inferior myocardium depends on the dominance. Hence awareness of these variations plays an important role in treating inferior wall infarcts. Also awareness of coronary artery variations is important during interventions like imaging by conventional catheters.

KEY WORDS: Posterior Interventricular Artery, Coronary Dominance, Right Dominance, Left Dominance, Balanced Dominance.

Address for Correspondence: Dr. Komala Nanjundaiah, Associate Professor, Department of Anatomy, M.S.Ramaiah Medical College, M.S.R Nagar, Bangalore 560054, Karnataka, India.

E-Mail: komas2001@yahoo.com

\section{Access this Article online}

\section{Quick Response code}

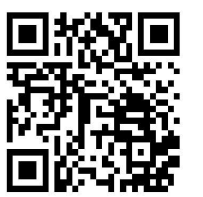

DOI: $10.16965 /$ ijar.2017.295

Web site: International Journal of Anatomy and Research ISSN 2321-4287

www.ijmhr.org/ijar.htm

Received: 15 June 2017

Peer Review: 15 June 2017

Revised: None
Accepted: 03 Aug 2017

Published (O): 31 Aug 2017

Published (P): 31 Aug 2017

\section{INTRODUCTION}

The heart is a hollow conical muscular organ, situated in the middle mediastinum. It is covered by pericardium. The heart which supplies blood to the entire body has to be supplied by coronary arteries. These coronary arteries are right and the left [1]. The right coronary artery (RCA) takes origin from anterior aortic sinus and terminates by anastomosing with circumflex branch of left coronary artery (LCA). Branches of right coronary artery are anterior atrial rami (sinu-atrial nodal artery), ventricular rami (right conus artery and right anterior ventricular rami, right posterior ventricular rami, posterior interventricular branch and right posterior atrial rami. The left coronary artery takes origin from left posterior aortic sinus. It divides into anterior interventricular, circumflex 
and diagonal artery [2]. Variations in the branching pattern of coronary arteries mainly affect the blood supply of the diaphragmatic surface of the ventricles. Based on the origin of posterior interventricular artery (PIVA), the relative dominance is described. If the PIVA arises from RCA, it is right dominance. If PIVA arises from LCA it is left dominance. If PIVA arises from both LCA and RCA it is termed as balanced pattern. Knowledge of normal and variant anatomy and anomalies of coronary arterial circulation becomes essential for treating heart diseases to get better outcomes [3]. Dominance becomes a major part in assessing prognosis of coronary artery disease [4]. Compared to right and mixed types of dominance, Left dominance is fatal [5]. The present study is done to note the origin and termination of PIVA. Based on the origin of PIVA, coronary dominance is documented.

\section{MATERIALS AND METHODS}

Source of data: Randomly selected 60 formalin fixed hearts (preserved heart specimens and hearts from cadavers which were used for dissection teaching) were obtained from the Department of Anatomy, M.S Ramaiah Medical College and few other medical colleges in Bangalore. These fixed heart specimens were dissected and studied over a period of two years.

Study design: Cross-sectional study

Sample size: Based on a study "Variations in coronary arterial system in cadaveric human heart" [6], it was found that $66 \%$ was right dominant and $23 \%$ was left dominant. So with power of $80 \%$ and confidence level of $95 \%$, the requisite sample size was estimated to 60 specimens.

Steps of dissection: The hearts from the cadavers were removed by cutting the ribs and sternum. The great vessels were ligated at two ends and then cut in between. The parietal pericardium was incised and heart along with great vessels was taken out of the pericardial cavity. All hearts were washed under running tap water to remove blood clots. The hearts were preserved in $10 \%$ formalin solution. All the hearts were tagged numerically. Coronary arteries and their branches were dissected in all hearts. Fat was removed from the coronary sulcus. Right coronary artery was traced from its origin, till it turns on the posterior surface of the heart. Then its branches were dissected on the posterior surface of heart. The left coronary arteries and their branches were identified. The PIVA, which passes along posterior interventricular groove, was found and its origin was noted. The course of PIVA up to the termination was traced. Any variation in origin and termination was recorded. Based on the origin of PIVA, whether from RCA or LCA or both, the coronary dominance was determined. The data was then tabulated. Statistical analysis was done. Ethical clearance for the study was obtained from the institutional ethical review board.

Inclusion criteria: Formalin fixed heart specimens with intact coronary arteries irrespective of age, sex or race.

Exclusion criteria: Lacerated or injured heart specimens with damaged coronary arteries, hearts with any surgeries of coronary arteries, maldeveloped hearts were excluded.

\section{RESULTS}

The present study was conducted in 60 specimens of cadaveric hearts and observed for number, origin, and level of termination of PIVA.

Coronary dominance was noted based on the origin of PIVA and tabulated as follows.

Table 1: Origin of posterior interventricular artery.

\begin{tabular}{|c|c|c|c|}
\hline SI. no & Origin of PIVA & Specimen & Percentage \\
\hline $\mathbf{1}$ & LCA (Fig-1a) & 4 & $6.70 \%$ \\
\hline $\mathbf{2}$ & RCA (Fig-1b) & 55 & $91.70 \%$ \\
\hline $\mathbf{3}$ & Both (Fig-1c) & 1 & $1.70 \%$ \\
\hline
\end{tabular}

Fig. 1a: Origin of PIVA from LCA, Fig. 1b: Origin of PIVA from RCA, Fig. 1c: Origin of PIVA from both LCA and RCA.
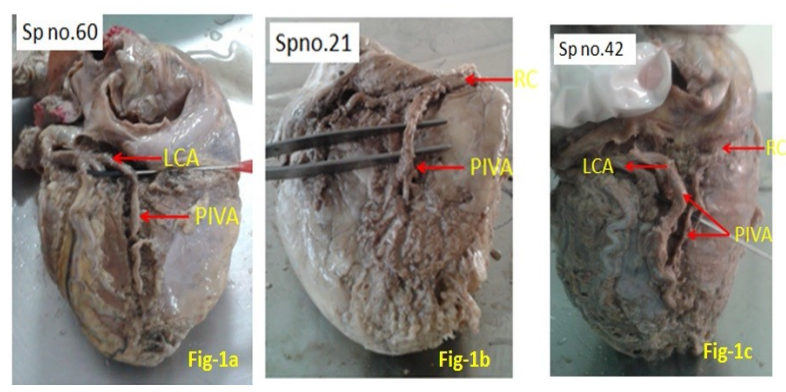

The termination of PIVA way down the posterior interventricular sulcus (PIVS) was noted as follows.

Table 2: Showing level of termination of PIVA originated from RCA.

\begin{tabular}{|c|c|c|c|}
\hline SI no. & Level of Termination of PIVA & $\begin{array}{c}\text { No of } \\
\text { Specimens }\end{array}$ & Percentage \\
\hline $\mathbf{1}$ & $1 / 4$ way down PIVS (Fig-2a) & 16 & $28.57 \%$ \\
\hline $\mathbf{2}$ & $1 / 2$ way down PIVS (Fig-2b) & 21 & $37.50 \%$ \\
\hline $\mathbf{3}$ & $3 / 4$ way down PIVS (Fig-2c) & 13 & $23.21 \%$ \\
\hline $\mathbf{4}$ & At apex (Fig-2d) & 6 & $10.71 \%$ \\
\hline
\end{tabular}


Fig 2a: Termination of PIVA at $1 / 4$ way down PIVS, Fig. 2b:Termination of PIVA at $1 / 2$ way down PIVS, Fig. 2c:Termination of PIVA at 3/4 way down PIVS, Fig. 2D: Termination of PIVA at apex.
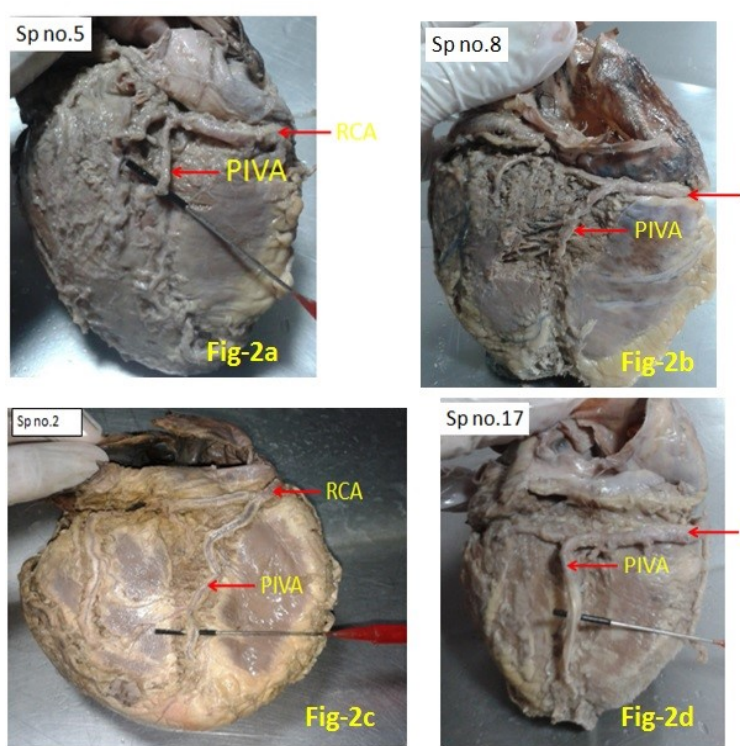

Table 3: Showing level of termination of PIVA originated from LCA.

\begin{tabular}{|c|c|c|}
\hline SI no. & Level of termination of PIVA & Specimen \\
\hline 1 & $3 / 4$ way down PIVS (Fig-2a) & 1 \\
\hline 2 & $1 / 2$ way down PIVS (Fig-2b) & 3 \\
\hline
\end{tabular}

Fig. 3a: Termination of PIVA at 3/4 way down PIVS, Fig. 3b: Termination of PIVA at $1 / 2$ way down PIVS.

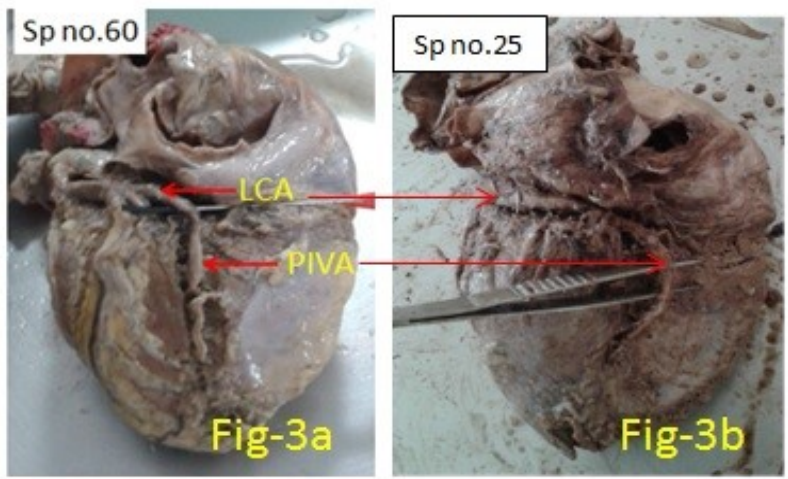

\section{DISCUSSION}

Heart contracts about one lakh times in a day. Coronary arteries which supply the heart begin to develop in utero around $3^{\text {rd }}$ week of embryogenesis. The steps of development include vasculogenesis, angiogenesis, arteriogenesis and remodeling. Due to this complexity involved during the development of coronary arteries, variations and anomalies are frequently seen. ${ }^{7}$ Anomalous origin of these arteries has important clinical manifestations. Dominance pattern of heart plays key role in various clinical conditions. On comparing with right \& mixed types of dominance, left dominance shows increased deaths. Inferior wall infarcts of the heart is related to dominance. ${ }^{5}$ Outcome of these infarcts can be determined by the extent of damage of the left ventricular myocardium. This is based on blood supply to the left ventricle. In right dominant hearts most of the left ventricle is supplied by left coronary artery. But in left dominant hearts the area supplied by left coronary artery is even more. Some anomalies of the coronary arteries can also cause sudden death especially in young athletes. ${ }^{8}$ Hence $t$ horough knowledge of normal and variant anatomy of coronary arteries is a prerequisite for clinicians to treat congenital, acquired, metabolic or degenerative heart diseases. ${ }^{3}$ Present study was conducted in 60 specimens and right coronary dominance was observed in 55 cases $(91.7 \%)$ which is similar with other studies. $3,9,10,11,12$, The incidence of left coronary dominance in present study was $6.7 \%$ which was also similar to earlier studies. ${ }^{10,11,13,14}$ In the present study, Co-dominance was found in $1.7 \%$. Comparison of the results of the present study with the results of the various other authors is as follows.

Table 4: Comparison of the origin of PIVA.

\begin{tabular}{|l|c|c|c|}
\hline \multirow{2}{*}{ Authors } & \multicolumn{3}{|c|}{ Origin of PIVA } \\
\cline { 2 - 4 } & RCA (\%) & LCA (\%) & BOTH (\%) \\
\hline Padmashree et al 2014 [12] & $89 \%$ & $11 \%$ & $0 \%$ \\
\hline Hirak Das et al 2010 [5] & $70 \%$ & $18.57 \%$ & $11.43 \%$ \\
\hline Kalpana 2003 [3] & $89 \%$ & $11 \%$ & $0 \%$ \\
\hline James 1958 [13] & $90 \%$ & $10 \%$ & $0 \%$ \\
\hline Nordon D G 2012 [11] & $88 \%$ & $8 \%$ & $4 \%$ \\
\hline Ballesteros 2011 [14] & $76 \%$ & $6.80 \%$ & $17.20 \%$ \\
\hline Jyoti P kulkarni 2013 [9] & $90 \%$ & $10 \%$ & $0 \%$ \\
\hline Nagaraj 2014 [10] & $90 \%$ & $6.67 \%$ & $3.33 \%$ \\
\hline Present study & $91.70 \%$ & $6.70 \%$ & $1.70 \%$ \\
\hline
\end{tabular}

The difference in percentage could be due to difference in sample size and different racial and geographical population. In present study PIVA which originated from the RCA terminated at $1 / 4$ way down PIVS in $28.57 \%, 1 / 2$ way down PIVS in $37.5 \%, 3 / 4$ way down PIVS in $23.21 \%$ and at apex in $10.71 \% .25 \%$ of the PIVA which originated from LCA terminated at $3 / 4$ way down PIVS, another $75 \%$ terminated at $1 / 2$ way down PIVS. When compared with the findings of the other authors termination of PIVA depicted no definite pattern. ${ }^{3,10,12}$ 


\section{CONCLUSION}

The coronary artery disease is one of the major causes of death. Both sedentary and stressful type of lifestyle is a risk factor. Coronary dominance is important because inferior wall myocardial infarctions are common. Outcome of these infarcts depends on the extent of damage of the left ventricular myocardium. In cases of blocks, revascularisation of these arteries demands sound knowledge about the normal and variant anatomy of the coronary arteries. PIVA has special importance as it determines the coronary dominance. Also awareness of these variations plays an important role during interventions like imaging by conventional catheters.

\section{ABBREVIATIONS}

RCA - right coronary artery

LCA - left coronary artery

PIVA - posterior interventricular artery

PIVS - posterior interventricular sulcus

\section{ACKNOWLEDGEMENTS}

I wish to express my sincere thanks to Dr.Shailaja Shetty, Professor \& head, department of Anatomy, M.S.Ramaiah Medical College for her encouragement $\&$ help extended to me during this study.

\section{Conflicts of Interests: None}

\section{REFERENCES}

[1]. Datta AK. Essentials of human anatomy: Thorax and Abdomen. $4^{\text {th }}$ ed. Vol 1. Kolkata: Current books international; 2009;62-81.

[2]. Williams PL, Banister LH, Berry MM, Collins P, Dyson $M$, Dussek JE, Ferguson MWJ. Gray's Anatomy In: Circulatory system. $38^{\text {th }}$ ed. USA: Churchill Livingstone; 1995;1505-10.

[3]. Kalpana, R. A study on the principal branches of coronary arteries in humans. Journal Of Anatomical Society of India. 2003;52(2):137-40.
[4]. Allwork SP. The applied anatomy of the arterial blood supply to the heart in man. Journal of Anatomy 1987;153:1-16.

[5]. Das H, Das G, Das DC, Talukdar K. A study of coronary dominance in the population of Assam. Journal of Anatomical Society of India. 2010;59(2):18791.

[6]. Bhimali S, Dixit D, Siddibhavi M, Shirole VS. A study of variations in coronary arterial system in cadaveric human heart. World J Sci Technol.2011;1:30-5.

[7]. Sadler TW. Langman's Medical Embryology. Cardiovascular system. $11^{\text {th }}$ ed. London: Lippincott, Williams and Wilkins; 2009;183-90.

[8]. Joshi SD, Joshi SS, Athavale SA. Origins of the coronary arteries and their Significance. Clinics 2010;65(1):79-84.

[9]. Kulkarni JP. Variant anatomy of coronary arteries. Heart India 2013;1(2):46-51.

[10]. Mallashetty N, Bhosale S, Bannur BM, Angadi AV. The study of dominance of coronary arteries in human heart, a cadaveric study. Anatomica Karnataka 2014;8(3):38-42.

[11]. Nordon DG and Rodrigues Junior OF. Variations in anatomy of coronary arteries. Journal of morphology science. 2012;29(3):178-181.

[12]. Chougle P, Silotry N, Chavan L. Variations in branching pattern of coronary arteries. 2014;3(8):270-3.

[13]. James TN and Burch GE. The Atrial Coronary Arteries in Man. Circulation.1958;17:90-8.

[14]. Ballestros LE, Ramirez LM, Quintero ID. Right coronary artery anatomy; Anatomical and morphometric analysis. Brazilian Journal of cardiovascular surgery. 2011;26(2):230-37.

How to cite this article:

Kannan Subramanian, Komala Nanjundaiah. STUDY OF POSTERIOR INTERVENTRICULAR ARTERY IN HUMAN CADAVERIC HEARTS. Int J Anat Res 2017;5(3.2):4238-4241. DOI: 10.16965/ijar.2017.295 